Ronald B. David, Candace H. David and Lisa S. Riley

The Medical College of Virginia, Department of Pediatrics, 5875 Bremo Road, Suite 700, Richmond, Virginia 23226; Email: vachildneuro @aol.com

Practical Neurology, 2003, 3, 150-159
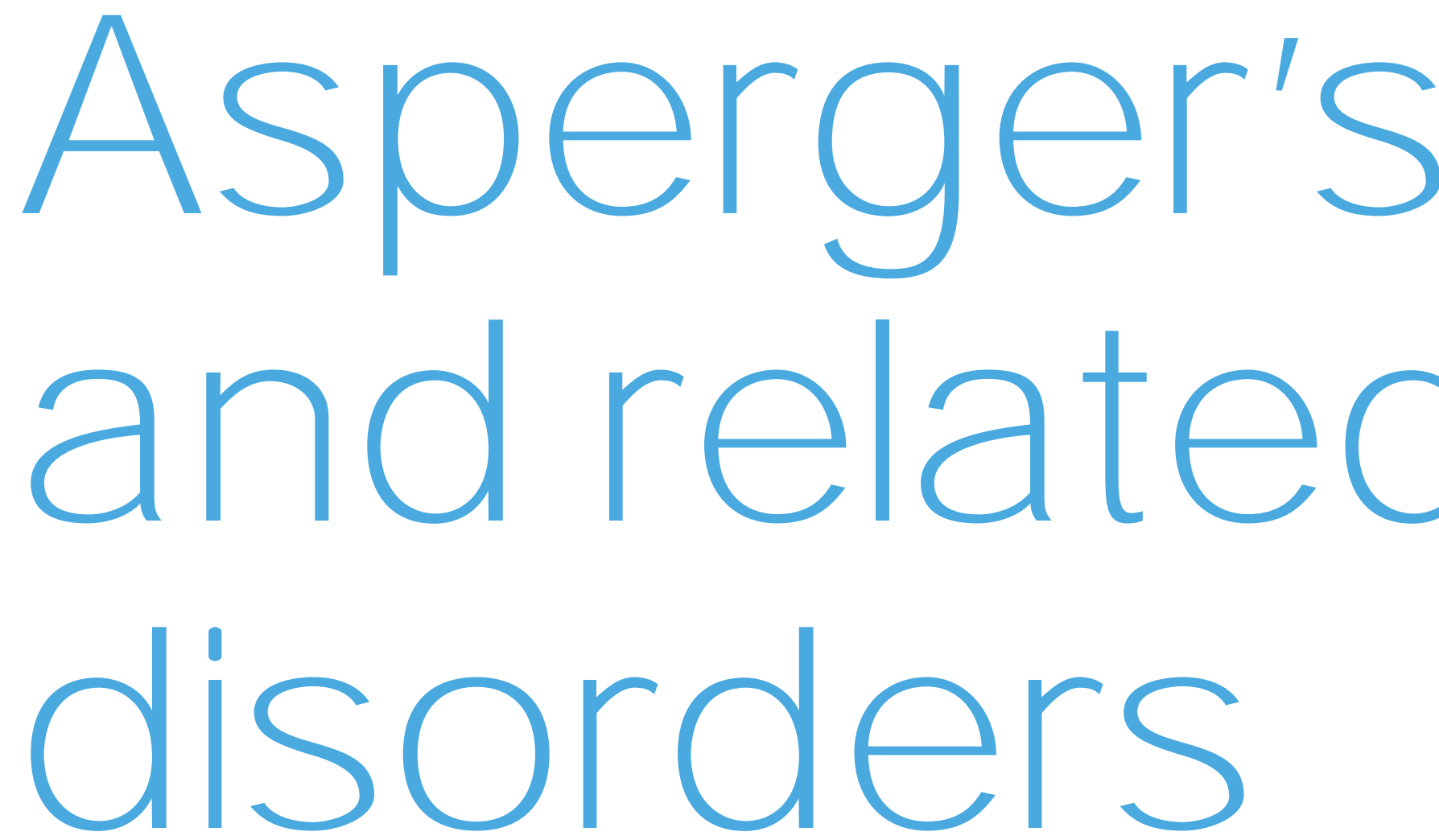

has increased dramatically. Asperger's disorder is defined, as is autism, in terms of social deficits, but early language and cognitive skills are preserved in Asperger's disorder'. Clearly there is overlap between the three disorders, but we believe there are sufficient phenomenological differences to discriminate between them.

Volkmar (2000) described thisboy asatypical example of Asperger's syndrome:

Robert (not his real name), age 11 years, eight months, was seen for evaluation at the request of his parents who were concerned that despite his apparent academic skills, Robert was increasingly isolated in school. He was the younger of two children born to his parents, both physicians. Robert was born after an uncomplicated pregnancy, labour and delivery. Heused his first words at one and spoke in sentences by 16 months. M otor skills were awkward and clumsy. Early on, hewas an avid reader who had read the Chronicles of Narnia in kindergarten. Social problems confronted Robert when heentered preschool at three years of age. He was socially inept and was seen quickly as an eccentric child. He was knowledgeable about astronomy to the point that this interest intruded on all aspects of his life. In conversation, he would shift the topic invariably or inevitably to this focus of his interest. Because of motor problems, he was evaluated by an occupational therapist. It was noted that hehad 'low motor tone'. A psychiatrist suggested at eight years of age that he had an anxiety disorder. Psychological testing at 10 years of age indicated a Verbal IQ of 145, a Performance IQ of 119 and a Full Scale IQ of 135 on the WISC-III. Because of continued visual-motor coordination problems including writing, he received occupational therapy and enrolled eventually in a program for gifted children. In a psychiatric mental status examination, 
Robert responded to adult greetings with appropriate, although very short, phrases. Hedid not respond to other people's facial expressions or gestures. He did not attend to social stimuli. He avoided eye contact and seemed to look through people. His emotional expressions lacked variability and modulation. When he described his interests in the universe, he became much more animated, but was difficult to redirect. $\mathrm{H}$ is thinking is not disorganized. $\mathrm{He}$ did not appear to be depressed. Hedid not exhibitunusual motor behaviours. Robert, in an autobiographical statement said: ' $M$ y name is Robert Edwards. I am an intelligent, unsociable, but adaptable person. I would like to dispel any untrue rumours about me. I am not edible. I cannot fly. I cannot usetelekinesis. M y brain isnot large enough to destroy the entire world when unfolded. I did not teach my longhaired guinea pig, Chronos, to eat everything in sight (that is the nature of the long-haired guinea)'.

An MRI scan (a T2-weighted) image, showed a 'focal hyperintesity about $1 \mathrm{~cm}$ in diameter without masseffect in theright middle temporal gyrus white matter just lateral to the optic radiations.

For the purposes of this review we have chosen to regard disorders of intuitive social competence as synonymous with pervasive developmental disorder (DSM -IV) and autism spectrum disorder (Rapin 1997). These are all defined by a fundamental lack of intuitivesocial skills believed to be secondary to weaknesses and differencesin being ableto perceiveanother individual's state of mind.

In clinical medicine it is highly desirable, but not always necessary (e.g. migraine) to define disease, disorder or syndrome by some biological marker. Without abiological marker, phenomenologically described conditions may not achievescientific validity as distinct entities. However, behavioural scientists believe these diseases, disorders or syndromes of intuitive social competence can be grouped phenomenologically, and that they haveboth faceaswell as consensual validity.

The following example may help make the point. A woman says she has been sexually active, is gaining weight and is no longer having menstrual periods. In this case a valid medical diagnosis can be made using only phenomenological observations. There is predictive valid-

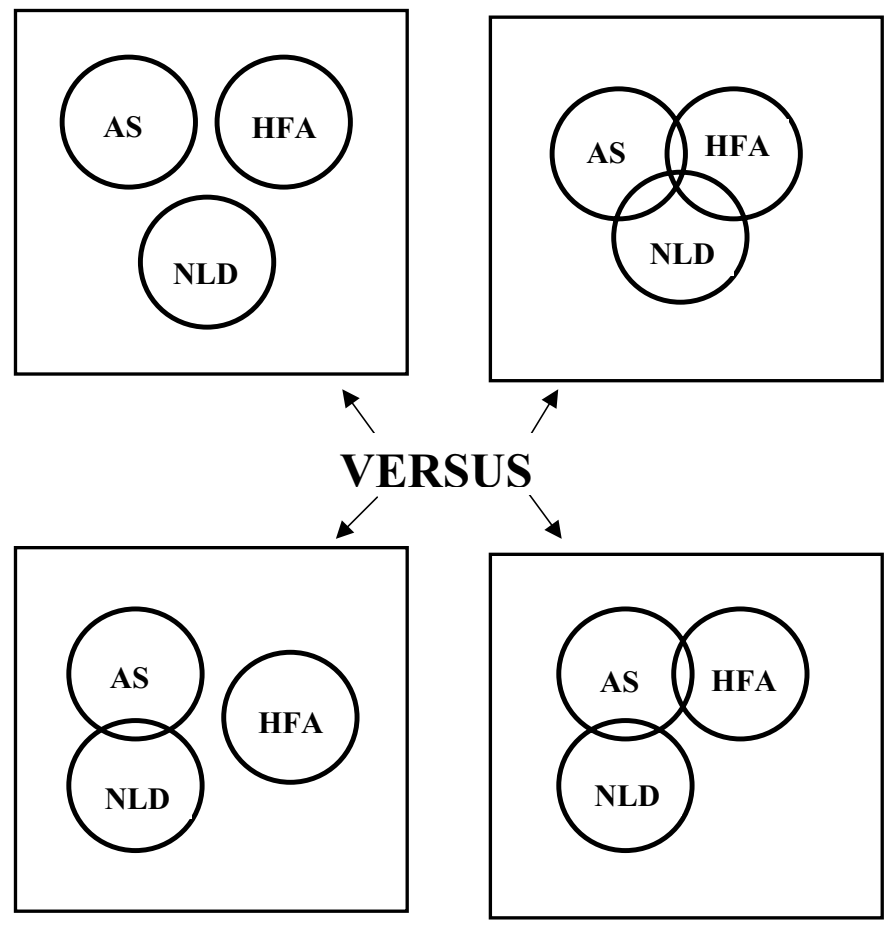

Figure 1 Various phenomenologically based views of the relationship between Asperger's syndrome, high functioning autism and non-verbal learning disability, showing that the core disorder is preserved in each. AS, Asperger's syndrome; NLD, non-verbal learning disability; HFA, high functioning autism.

ity, as well as a biological marker to externally validate the phenomenologically deduced diagnosis. Unfortunately, thereare no such sharp diagnostic boundaries in disorders of intuitive social competence, but the existence of a core is virtually undisputed by most behavioural scientists. Of course, overlap at theperipheriesallows considerable confusion and controversies to arise as behavioural scientists attempt to clarify the periphery, and begin to delineate subtypes. For the purposes of our discussion these contrasting subtypes are high functioning autism and non-verbal learning disability. The different ways in which they may or may not overlap is presented graphically (Figure 1), but the core disorder is preserved in each figure.

Klin et al. (1995) has suggested that nonverbal learning disability and Asperger's syndrome have many features in common which help discriminate them from high functioning autism. At least average verbal intellectual potential (Verbal IQ) and a significant discrepancy between intellectual potential (Full Scale IQ) and attainment on measures of non-verbal performance (Performance IQ) characterize non-verbal learning disability (Table 1). But, it is not a unitary disorder and patients have a 
Table 1 Non-verbal learning disability

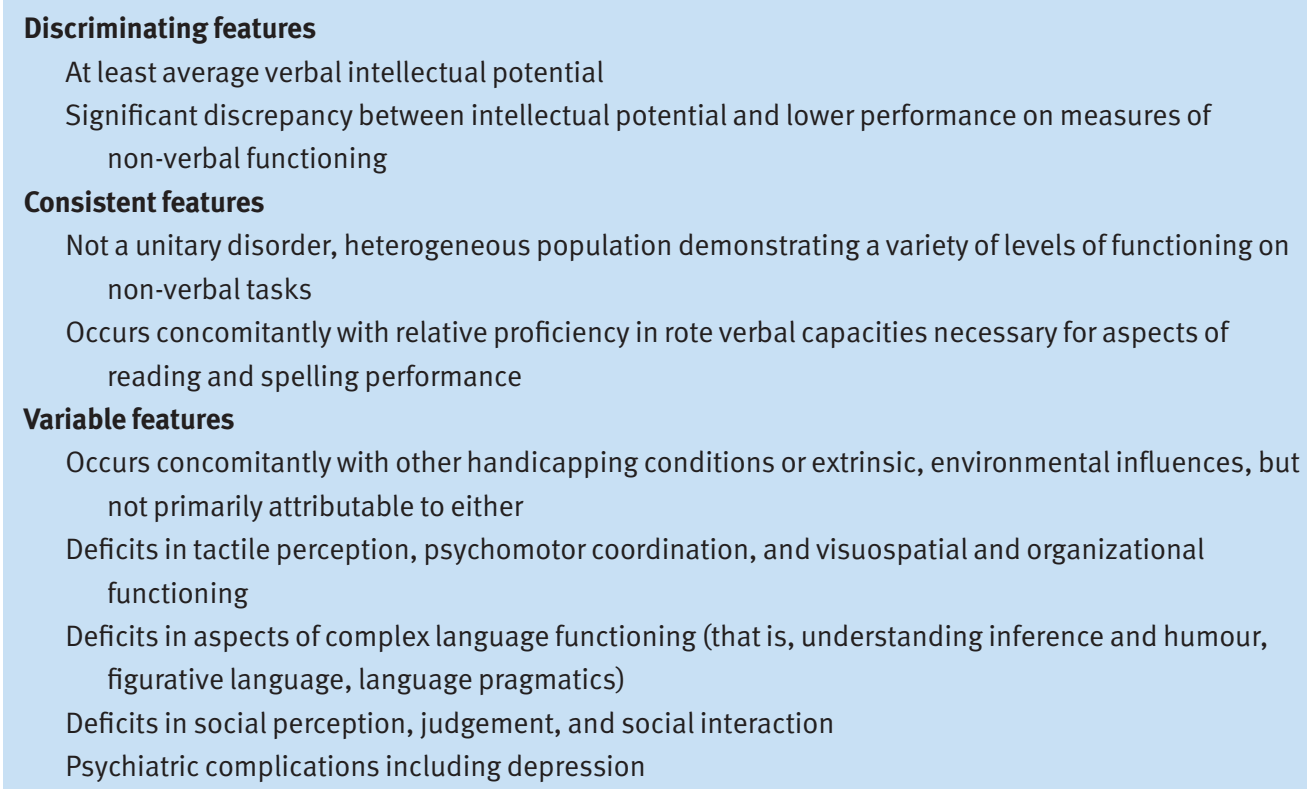

Not a unitary disorder, heterogeneous population demonstrating a variety of levels of functioning on non-verbal tasks

Occurs concomitantly with relative proficiency in rote verbal capacities necessary for aspects of reading and spelling performance

\section{Variable features}

Occurs concomitantly with other handicapping conditions or extrinsic, environmental influences, but not primarily attributable to either

Deficits in tactile perception, psychomotor coordination, and visuospatial and organizational functioning

Deficits in aspects of complex language functioning (that is, understanding inference and humour, figurative language, language pragmatics)

Deficits in social perception, judgement, and social interaction

Psychiatric complications including depression

Table 2 High functioning autism

\section{Discriminating features}

Qualitative impairment in intuitive social interactions

Average or below average overall intelligence (Performance IQ $\geq$ Verbal IQ)

\section{Consistent features}

Pragmatic language disorder

Odd stereotyped motor movements

General delay in language development

More often diagnosed in boys than girls

Hyptonia (gross motor skill deficit)

\section{Variable features}

Echolalia

Impaired use of non-verbal behaviours

Above average material specific visuospatial and visuomotor skills

Hyperlexia (the precocious self-taught ability to read words with an apparent lack of comprehension) variety of levels of ability on non-verbal tasks. In contrast, relative proficiency is retained in rote verbal capacity, which isnecessary for aspects of reading and spelling performance. Frequently, though not always, there are deficits in tactile perception, coordination, visuospatial and organizational functioning. The overlap with Asperger's syndrome and high functioning autism occurs because of other common though individually variable features, including deficits in complex languagefunctions, i.e. understanding inference, humour, figurative language, and language pragmatics. Deficits in social perceptual judgements and reciprocity occur in all three disorders.

Children with high functioning autism (Table 2) must have the DSM -IV criteria, primarily impairments of social interaction such as:

- the use of non-verbal behaviours;

- failure to develop peer relationships;

- lack of sharing enjoyment and interest achievement;

- lack of social emotional reciprocity.

And impairments in the communication domain:

- delay in language development;

- inability to initiate or sustain conversation;

- echolalia/jargon;

- impaired imaginative play. 
Thesechildren al so haverestricted activities and interests suggested by:

- excessive preoccupations with certain interests;

- inflexible routines or rituals;

- stereotyped motor mannerisms;

- preoccupations with parts of objects.

In high functioning autism, the Full Scale IQ may be in the average range, below average or even in the retarded range $(<70)$. H owever, these measurably retarded high functioning autistic children have functional skills that clearly distinguish them from their moreglobally (both measurably and functionally) retarded counterparts. They are verbal - even verbose - but al ways in our opinion exhibit some continuing and omnipresent language disability. This disability may only affect language pragmatics (see below) and/or prosody.

Children with Asperger's syndrome (Table 3) have significantly higher overall Full Scale IQ and Verbal IQ compared with their inferior Performance IQ . Asperger's syndromechildren frequently have non-verbal writing disabilities. The DSM -IV suggests that Asperger's children have qualitative impairment in social interac-

Table 3 Asperger's syndrome

\section{Discriminating features}

Qualitative impairment of intuitive social interaction

Above average overall intelligence (Full Scale IQ) with Verbal IQ significantly greater than Performance IQ

\section{Consistent features}

Gross and material specific motor skill deficit

Pragmatic language disorder (at the discourse level)

Loquaciousness

Restricted interests

Age-appropriate self-help skills, adaptive

More common in boys than girls

No general delay of language development

No schizophrenia

No odd stereotyped motor movements

\section{Variable features}

Impaired use of non-verbal behaviours

Failure to develop peer relationships

Lack of social or emotional reciprocity

Inflexible adherence to rituals or routines

Above average, material specific visuospatial and visuomotor skills (e.g. puzzles, lego) Hyperlexia (discrepancy between reading comprehension and word reading abilities;

frequent literal interpretation)

Features of Non-verbal Learning Disorder

No verbal memory deficits tion manifest by at least two of the four following

- impairment in the use of non-verbal behaviours to regulate social interactions;

- failure to develop peer relationships;

- lack of spontaneous seeking to share enjoyments and interests;

- lack of social or emotional reciprocity.

They also have restricted, repetitive and stereotyped patterns of behaviour, interests and activities, as manifest by at least one of the following:

- encompassing preoccupation with one or more stereotyped and restricted patterns of interest that is abnormal either in intensity or focus;

- apparently inflexible adherence to specific, non-functional routines or rituals;

- stereotyped and repetitive motor mannerisms (i.e. hand flapping, finger tapping or twisting, complex whole-body movements);

- persistent preoccupations with parts of objects.

The disturbance causes clinically significant impairment in social, occupational, or other important areas of functioning.

Thereis no clinically significant general delay in language (e.g. single words used by two years of age, communicative phrases used by three years of age).

There is no clinically significant delay in cognitive development or in the development of age-appropriate self-help skills, adaptive behaviour (other than in social interaction) and curiosity about the environment in childhood.

\section{Language pragmatics}

Language pragmatics mean the understanding of unspoken conversational rules and the ability to discern or express communicative intent (meaning). In Asperger's syndrome, as in high functioning autism, the use of language is impaired, notably in narrative and conversational discourse, and at a minimum pragmatics and/or prosody is affected. In our own experience, the degree of functionality or disability is related to the verbal ability (Verbal IQ).

By three years of age, children should be able to:

- request actions;

- request objects;

- makeassertions;

- makedenials;

- request information; 
- request assistance;

- stateinformation;

- appropriately use or respond to who, what, whereand how questions.

But children with pragmatic languagedisorders often have difficulty:

- letting others know when they have not been understood (requesting clarification);

- responding specifically or with relevancy (tend to produce tangential comments);

- speaking clearly (or conveying information that is clear and understandable, without presupposing information on the part of the listener);

- adjusting their speech for a given context - sensitivity to listener needs;

- expressing social intentions (e.g. greetings);

- producing coherent discourse (e.g. well organized presentations of information and appropriate use of non-verbal signals);

- learningand applyingtherules of socio-emotional expression;

- initiatingand sustaininga conversation apart from in their own intense areas of interest.

Few formal or standardized instruments have been developed to test language pragmatics and thosethat areavailable often fail to observeindividualsin adynamic social context. Consequently,assessmentisgenerallyinformal, unstructured, less than comprehensive and therefore inexact. Nonetheless, it is our experience that language pragmatics are invariably affected in Asperger's syndrome and high functioning autism. Topic maintenance is the most apparent discourse deficit in Asperger's syndrome while difficulties with social and presuppositional judgement, sensitivity to listener needs, and appreciation of context are most apparent in high functioning autism (Twachtman-Cullen 2000).

\section{Social pragmatics}

Social pragmatics broadly define the mechanisms by which human interaction occurs. A significant part of thisinteraction requiresintact linguistic and pragmatic language skills. Social pragmatics has the same conventions (rules) as language pragmatics, but encompassesnon-verbal communications. Children with disorders of intuitive social interaction competence have deficits in social pragmatics, verbal and nonverbal, which clearly distinguishes them from their intuitively socially competent peers.

\section{Idiosyncratic behaviours}

Behaviour in Asperger's syndrome and high

Language pragmatics

\section{mean the understanding}

\author{
of unspoken
}

conversational rules and

the ability to discern or

express communicative

intent (meaning)

functioningautism isfrequently odd or idiosyncratic, because these individuals do not intuitively understand another person's state of mind or sense the negative reaction of others to their oddness and inappropriate behaviours. Adventitious motor movements such as tics or motor stereotypies, including persistent toe walking, hand flapping and rocking are frequently seen in high functioning autism, but, in our opinion, almost never in Asperger's syndrome or nonverbal learning disability.

\section{Normal but odd}

At thefar end of the disorders of intuitive social competence continuum is what may be termed 'normal but odd'. We must all have either met or know of people who, although highly intelligent, lack social graces and may even have behavioural idiosyncrasies. Recently, a mother of achild withAsperger'ssyndromewho professionally teaches the gifted, reflected on the nature of her child's disability. She suggested that in her class for gifted children, even while some of them exhibited behavioural idiosyncrasies and werethesubject of ridicule, they each could develop dialogue and a social bond around a common area of interest. Her own child found it difficult, if not impossible, to find individuals with whom hecould sharehis interests for long, or at all.

\section{NEUROPSYCHOLOGICAL AND PSYCHOLOGICAL ASPECTS}

Children with Asperger's syndrome have average, above average or even superior Full Scale 
IQ with Verbal IQ significantly higher than Performance IQ. In contrast, the Full Scale IQ of children with high functioning autism may be above average, average or even below. Although high functioning autism children can be superficially verbose or functionally superior, their measured IQ often falls in the retarded range. Their non-verbal skills are equal or higher than their verbal skills, irrespective of their Full Scale IQ, while in non-verbal learning disability, the Full Scale IQ is above average, or average with a bigdifference( often 12 or morepoints) between a higher Verbal IQ and a lower PerformanceIQ . Our clinical experience suggests, however, that non-verbal learning disability children have a range (average to above average) in Full Scale IQ in contrast to Asperger's syndrome where the IQ is generally above average, and their clinical symptomatology more closely resembles Asperger's original descriptions. There are additional treatment implications because the non-verbal learning disabilitychildren aremore likely to have significant academic difficulty compared with Asperger's children.

The concept of non-verbal learning disability viewed from the standpoint of a compre hensive neuropsychological profile includes not only the significant discrepancy between Verbal and Performance IQ, but also deficits in visuospatial organization, visuoperceptual, psychomotor and non-verbal problem solving and concept-formation skills. These children have neuropsychological assets in psycholinguistic skills such as verbal learning, regular phoneme-grapheme matching, amount of verbal output and verbal classification. M ajor learning disabilities are seen in mechanical arithmetic and advanced levels of word recognition and spelling. Thereis strong evidence to suggest that virtually all the characteristics of non-verbal learning disability are seen in some children with Asperger's syndrome. These convergent characteristics, along with the more typical Asperger's symptomatology, may help distinguish these children from high functioning autism.

To repeat, Asperger's syndrome, high functioning autism and non-verbal learning disability may overlap, converge or in other ways blend but they appear to have a sound phenomenologically based core. Asperger's and high functioning autism are the most distinct and clearly separate from each other. Whether non-verbal learning disability is a 'stand alone' entity or totally converges with Asperger's syndrome remains to be seen. We believe that the above average IQ, particularly the Verbal IQ, seen in Asperger's syndrome, contributes to the 'Little Professor' stereotype, discriminating it from non-verbal learning disability where the children are not nearly as verbose, and do not engage in excessive questioning, non-verbal learning disability children are less verbally focused and organized, and their maladaptive socio-emotional disorders are different.

\section{GENETICS}

There is general consensus that disorders of intuitive social competence have a significant genetic component, with a recurrence risk of $3-8 \%$ in families with one affected child who is autistic (Rapin 1997). In Asperger's syndrome, up to $33 \%$ of first degree relatives have 'social difficulties' (Volkmar et al. 1998). However, no consistent genetic or chromosomal abnormalities have been identified. There are many multiplex families, often with highly variable symptomatology. These children may even be identical or fraternal twins. Wehavein our practice a number of families with three (and in one family, four) affected children. Ultimately there may beno singlegenotype, a point suggested by the fact that there are some Down syndrome children who meet criteria for high functioning autism.

\section{NEUROIMAGING}

The findings in the case of Robert are unusual but the location is of interest, as the right middle temporal gyrus and the adjacent superior temporal sulcus play a key role in facial expression and thedirection of eyegaze. Children with autism and Asperger's syndrome have head circumferences above average and at times frank macrocrania or megancephaly. The head may not be large at birth, but grows at an increasingly rapid rate. Brain volume on neuroimaging is larger overall when compared with normal children (Filipek 2000). H owever, routineneuroimagingiscontroversial - consistent abnormalities have not been found (Filipek 2000).

\section{ELECTROENCEPHALOGRAPHY}

Theprevalence of epilepsy in autistic children is 7- $14 \%$. There is also a higher frequency of epileptiform abnormalities on the EEG in autistic children showing early language regression (Filipek 2000). 


\section{Children with Asperger's}

\section{simply lack the capacity to}

articulate fears, concerns

or ideas beyond a short

response unless the query

taps even tangentially into

their area(s) of expertise important because of the frequent concurrent psychiatric disorders, including severe depression.

Thediagnosisof high functioningautism may be made by the use of parent-teacher report or observation rating scales. In-depth discussions of thesecan befound in Filipek (2000).

Recommended instruments include:

- parent interviews;

- The Gilliam Autism Rating Scale;

- TheParent Interview for Autism;

- The Pervasive Developmental Disorders Screening Test Stage 3;

- TheAutism Diagnostic Interview.

The diagnostic observation instruments include:

- TheChildhood Autism Rating Scale;

- The Screening Tool for Autism in Two Year Olds;

- The Autism Diagnostic O bservation Schedule-Generic.

These instruments should enable clinicians to determine whether diagnostic criteria have been met. This diagnostic standard is therefore criterion-based. Tables 1-3 propose a discriminator based system. Identifying biological markers in these disorders would be the preferred approach to diagnosis. H owever, from a teaching/understanding point of view, even if phenomenologically based, these tools can still beuseful. They should be viewed as a best effort given the'state-of-theart' and arethereforeonly a point of departure. Therearebound to berevisions as moreknowledge emerges.

\section{MANAGEMENT}

\section{General}

Because children with Asperger's are so verbal, teachers, parents and others assume they can be reasoned with using verbally mediated questions and answers. They cannot understand why the most common response to any 'who', 'why', 'where', 'when' or 'how' questions is, 'I don't know.' When one recalls that these children lack intuitive pragmatic language skills, their responseis understandable. Children with Asperger's simply lack the capacity to articulate fears, concerns or ideas beyond a short response unless thequery tapseven tangentiallyinto their area(s) of expertise. Because they do not know how to respond they may beaccused of not paying attention, being unconcerned, oppositional or defiant. The oppositional-defiant response behaviour soon generalizes to all behaviours to 
thefrustration of caregiversand teachers. M edications, often multipleand in increasingly large doses, are expected - wrongly - to impact on what is essentially a communication problem.

Therefore, social learning must use an operant behaviour consequence approach. Lacking intuitive social skill, the Asperger's child must be taught using a rule-based approach be it for purposes of discourse or social intervention, such as the concept of personal space or appropriate touching. Civilized society has numerous rules, many of which are enforced without explanation. A rule-based method in a natural settingsimply emphasizes this approach over onerelying on insight. Human nature usually compels caregivers to provide a rationale for their requests or demands. While it may be crass to say so, unfortunately this is often literally a waste of time and breath with Asperger's children. Compassionate firm and consistent rule setting is difficult but necessary. 'You broke the rule and you know the consequences that you can expect.' M any children with Asperger's syndromeenjoy rules just as much as they enjoy ritualsand preservation of sameness. I nvariably, theseruleswill takeon alife of their own, and the child's focus will shift to therulerather than the rulemaker. This allows therulemaker to escape being seen as the villain.

Language (verses speech) therapy should focus on developing pragmatic language skills, if need be employing a rote methodology. Psychological counselling should emphasize setting standards for social interaction rather than relying on an insight-orientated approach. Family involvement is critical.

\section{Education}

At school, we have found that providing an Asperger's child with an individual adult trainer, mentor or shadow is important initially. This individual should have special training in working with thesechildren. Theservices of this individual can be faded out as the child adjustment improves. In later school years, ridiculeincreases and becomes, in our experience, almost totally impossibleto control. This, with 'change' of any kind, leads to great anxiety. The ultimate solution may beasmall school with an excellent staffing/pupil ratio. This setting is essentially a 'club' where acceptance is guaranteed and often includes other children with the same disability. The last place these emotionally vulnerable children should beisin a classfor emotionallyor behaviourally disturbed children. An Asperger's child becomes in this context, theperfect victim with skilled victimizers.

\section{Pharmacotherapeutic agents}

There is no traditional or non-traditional remedy or cure for Asperger's syndrome. Pharmacotherapeutics do not target the primary deficit but can beused as adjunctive agents. The stimulants (e.g. methylphenidate, dextroamphatamine) can enablethechild to better attend or focus and thus indirectly improve behaviour. An agent such as clonidinecan beused for anxiety, pre-emptively or for sleep. In thissituation it appears to have a predictable response.

Neuroleptics can be used in extreme situations, but the long-term risk of tardive dyskinesia limits their usefulness. Selective serotonin reuptakeinhibitors and antiepileptic agents can be used as 'mood stabilizers'. In our experience these agents have an inconsistent effect and a dramaticresponseisvery infrequent. It isparticularlyimportantin thesechildren to 'start (very) low and go (very) slow.' They do not adjust well to any changes and this may account in part for exaggerated responses to even thesmallest dose of any medication.

\section{Parent and patient information}

Http://yale.med.info/chidstdy/autism

\section{ACKNOWLEDGEMENTS}

We thank M rs M artha Horne for her help in manuscript preparation.

\section{REFERENCES}

American Psychiatric Association (1994) Diagnostic and standard manual of mental disorders, 4th edn. American Psychiatric Association: Washington D.C.

Asperger H (1944) Die 'aitostochen \{sujp;[atjen' Im Kindersalter. Archive fur Psychiatrie und Nervenkheiten, 117, 76-136.

Filipek PA, Accardo PJ, Asinwal S et al. (2000) Practice parameter: Screening and diagnosis of autism. Report of the Quality StandardsSubcommittee of theAmerican Academy of N eurology and the Child Neurology Society. Neurology, 55, 465-79

Kanner L (1943) Autistic disturbances of affective contact. Nerv Child, 2, 217-50.

Klin A, Volkmar FR, Sparrow SS, Ciochetti DV \& Rourke B (1995) P Validity and neuropsychological characterization of Asperger syndrome: Convergence with nonverbal learning disabilities. Journal of Child Psychology and Psychiatry, 36, 1127-40.

Rapin I (1997) Autism. New England Journal of M edicine, 337, 97-104.

Rourke BP (1989) N onverbal Learning Disabilities. The 
Syndrome and the M odel. The Guildford Press, New York.

RourkeBP, Fisk JL \& StrangJD (1986) Neuropsychological assessment of children: A Treatment-Oriented Approach. The Guildford Press, New York.

Twachtman-Cullen D (2000) M ore Able Children with Autism Spectrum Disorders. In: Communication and Language Intervention Series. Autism Spectrum Disorders: a Transactional Developmental Perspective, Vol. 9 (eds Prizant B \& Wetherby A), pp. 229-40. Paul H . Brookes Publishing Co, M aryland.

Volkmar FR, Klin A \& Pauls D (1998) Nosological and genetic aspects of Asperger syndrome. Journal of Autism and Developmental Disorders, 28, 457-63.

Volkmar F, Klin A, Schultz RT, Rubin E \& Bronen R (2000) Asperger's Disorder. American Journal of Psychiatry, 157, 2.

Wing L (1981) Asperger syndrome: a clinical account. Psychological Medicine, 11, 115-29.

\section{FURTHER READING}

Bauman M L (1992) Motor Dysfunction in autism. In: M ovement Disorders in Neurology and N europsychiatry (edsJ oseph AB \& Young RR), pp. 658-61. Blackwell Scientific, Boston.

Bishop DVM (1989) Autism, Asperger's syndrome and semantic-pragmatic disorder: Wherearetheboundaries? British Journal of Disorders of Communications, 24, 107-21.

Bowman EP (1986) Asperger's syndrome and autism: The case for a connection. British Journal of Psychiatry, 152, 377-82.

Kerbeshian J, Burd L, Risher W (1990) Asperger's syndrome: to beor not to be? British Journal of Psychiatry, 156, 721-5.

Klin A (1994) Asperger syndrome. Child and Adolescent Psychiatry Clinic of North America
Klin A, Volkmar FR (2000) Treatment and intervention guidelines for Individuals with Asperger Syndrome. In: Asperger Syndrome (eds Kiln A, Sparrow SS, Volkmar FR), pp. 000. The Guildford Press, N ew York.

Klin A \& Volkmar FR (1997) Asperger Syndrome. In: $\mathrm{H}$ andbook of Autism and Pervasive Developmental Disorders, 2nd edn. (eds Cohen DJ \& Volkmar FR), pp. 94-122. John Wiley $\&$ Sons, New York.

Landa R (2000) Social Language Use in Asperger Syndrome and High-Functioning Autism. In: Asperger Syndrome (eds Klin A, Volkmar F \& Sparrow S), pp. 127-45. The Guilford Press, New York

Lord C \& Venter A (1992) O utcomeand follow-up studies of high-functioning autistic individuals. In: High Functioningl ndividualswith Autism (edsSchopler E \& M eslibov GB), pp. 187-99. Plenum Press, New York.

Ozonoff S, RogersSJ \& Pennington BF (1991) Asperger's syndrome: evidence of an empirical distinction from high-functioning autism. Journal of Child Psychological Psychiatry, 32 1107-22.

Ritvo ER, Jorde LB, M ason-Brothers A et al. (1989) The UCLA-University or Utah epidemiologic survey of autism: recurrence risk estimates and genetic counseling. American Journal of Psychiatry, 146, 1032-6.

Szatmari P, Bremner R \& Nagy JN (1989) Asperger syndrome, A review of clinical features. Canadian Journal of Psychiatry, 34, 554-60.

Szatmari P, Bartolucci G \& Bremner R. (1989) Asperger's syndrome and autism: comparison of early history and outcome. Developmental M edicine Child Neurology, 31, 709-20.

Waterhouse L, M orris R, Allen DA et al. (1996) Diagnostic and classification in autism. Journal of Autism Disorders, 26, 59-86.

Woodhouse W, Bailey A, Rutter M et al. (1996) Head circumference in autism and other pervasive de velopmental disorder. Journal of Child Psychological Psychiatry, 37, 665-71. 